\title{
Associations among blood pressure, salt consumption and body weight status of students from south-western Ontario
}

\author{
Sarah J Woodruff' ${ }^{1, *}$, Katherine Fryer ${ }^{2}$, Ty Campbell ${ }^{3}$ and Mary Cole ${ }^{2}$ \\ 'Department of Kinesiology, University of Windsor, 401 Sunset Avenue, Windsor, ON N9B 3P4, Canada: \\ ${ }^{2}$ Faculty of Nursing, University of Windsor, Windsor, ON, Canada: ${ }^{3}$ Faculty of Education, University of \\ Windsor, Windsor, ON, Canada
}

Submitted 19 July 2012: Final revision received 10 January 2013: Accepted 22 January 2013: First published online 4 March 2013

\begin{abstract}
Objective: The purpose was to examine the associations among body weight status, blood pressure and daily $\mathrm{Na}$ intake among grade 7 students from south-western Ontario, Canada.

Design: Cross-sectional. Data were collected using the Food Behaviour Questionnaire, including a $24 \mathrm{~h}$ diet recall. Measured height and weight were used to determine BMI. Blood pressure was taken manually using mercury sphygmomanometers.

Setting: Twenty-six schools in south-western Ontario, Canada.

Subjects: Grade 7 students ( $n$ 1068).

Results: Body weight status indicated 1\% were underweight, 56\% normal weight, $23 \%$ overweight and $20 \%$ were obese. Mean systolic blood pressure (SBP) and diastolic blood pressure (DBP) were 108.3 (sD 10.3) $\mathrm{mmHg}$ and $66 \cdot 0$ (SD 7.5) $\mathrm{mmHg}$, respectively, and mean $\mathrm{Na}$ intake was 2799 (SD 1539) mg/d. Bivariate analyses suggested that SBP $(P<0 \cdot 001)$ and DBP $(P<0 \cdot 001)$ were significantly different by body weight status, yet no associations were observed for Na. Adjusted for gender, ethnicity and under-reporting, participants were more likely to be overweight/obese if they had higher SBP $(v$. lower: OR $=1 \cdot 06,95 \% \mathrm{CI} 1 \cdot 05$, $1 \cdot 08, P<0 \cdot 001)$, higher DBP $(v$. lower: OR $=1 \cdot 02,95 \%$ CI 1·00, $1 \cdot 04, P=0 \cdot 043)$ and higher intakes of $\mathrm{Na}$ (3rd $v$. 1st quartile: $\mathrm{OR}=1 \cdot 72,95 \% \mathrm{CI} 1 \cdot 14,2 \cdot 59$, $P=0 \cdot 009$; 4th $v$. 1st quartile: $\mathrm{OR}=2 \cdot 88,95 \% \mathrm{CI}, 1 \cdot 76,4 \cdot 73, P<0 \cdot 001)$.

Conclusions: High intakes of $\mathrm{Na}$, coupled with high SBP and DBP, were associated with overweight and obesity status among the grade 7 sample from south-western Ontario, Canada.
\end{abstract}

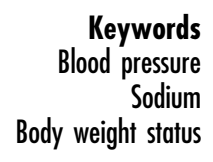

Body weight and related health issues among Canadian children and adolescents are of growing concern for health professionals. In the past, hypertension was believed to be a concern directed to the adult population, yet researchers around the world are beginning to study the associations between BMI and blood pressure (BP) in children and adolescents to predict future cardiovascular risks. Although the most recent national data suggest that only $2 \cdot 2 \%$ of Canadian children/adolescents (aged 12-19 years) have high $\mathrm{BP}^{(1)}$, other studies have reported high BP among 3-13\% of Canadian youth ${ }^{(2-5)}$. However, all studies have used different methods to classify high BP in youth, since no recognized standards exist and/or have been agreed upon.

Salvadori et al. ${ }^{(5)}$ reported being overweight or obese to be strongly associated with high BP in Canadian children after adjusting for a family history of hypertension and kidney disease. Further, Gopinath et $a l^{(6)}$ recently reported high BP among $21 \%$ of overweight/obese pre-school children (3-6 years old, $n$ 1294). High BP levels are thought to track from childhood to adulthood ${ }^{(7-9)}$, which may increase cardiovascular health risk in the future. Furthermore, high BP tracking seems to be even stronger among overweight and obese youth ${ }^{(10-12)}$.

Several recent studies have investigated the impact of various lifestyle behaviours on $\mathrm{BP}^{(13-15)}$, albeit mainly physical activity behaviours. For example, using the International Children's Accelerometry Database (i.e. aged 4-18 years), Ekelund et al. ${ }^{(13)}$ reported that greater amounts of time spent in moderate-to-vigorous physical activity was associated with better cardiometabolic risk factors (including BP) regardless of the amount of sedentary time. Furthermore, Stabelini Neto et al. ${ }^{(16)}$ observed the metabolic syndrome (high waist circumference, high BP, low HDLcholesterol, high TAG and high fasting plasma glucose) among inactive children/adolescents ( 14 years old, $n$ 456). However, very little evidence exists on the associations between BP and nutrition among children/adolescents. 
According to the Canadian Community Health Survey $2 \cdot 2^{(17)}$, the median $\mathrm{Na}$ intake for 9-13-year-olds was $3515 \mathrm{mg} / \mathrm{d}$ and $2959 \mathrm{mg} / \mathrm{d}$ for males and females, respectively, and approximately $97 \%$ (males) and $82 \%$ (females) had $\mathrm{Na}$ intakes above the Tolerable Upper Intake Level (UL is $<2200 \mathrm{mg} / \mathrm{d}$ ). Other Canadian studies have also reported high $\mathrm{Na}$ intake levels ${ }^{(18,19)}$, suggesting important possible health implications. Among adults, reducing $\mathrm{Na}$ intake is a common recommendation for hypertension, yet it is unclear whether $\mathrm{Na}$ is associated with BP in children/adolescents.

Furthermore, the prevalence of high body weight status is concerning among Canadian children and adolescents. Researchers and clinicians are striving to understand this potentially deleterious health concern. Very little work has investigated the potential negative associations of high $\mathrm{Na}$ consumption in children/adolescents. Therefore, the purpose of the present study was to examine the associations among body weight status, $\mathrm{BP}$ and daily $\mathrm{Na}$ intake among grade 7 students from south-western Ontario, Canada.

\section{Participants and methods}

All methods and procedures were approved by the University of Windsor Research Ethics Board, the Windsor Essex County Health Unit Research Ethics Board and each school board. Schools were chosen from two school boards (i.e. ninety-eight possible schools) and were selected to represent a cross-section of neighbourhoods based on a comparison of socio-economic and demographic variables (e.g. forward sortation code from the school's postal code) from the 2006 Census Tract Profile. The desired sample size was thirty schools but due to timing, twenty-six schools participated (at the school level, there were thirteen refusals to participate mainly due to timing of the study during the school year). All students in grade 7 were targeted, yet due to split classrooms, some grade 6 and grade 8 students were invited to participate. Out of a potential 1208 students from twenty-six schools, 1068 students participated (i.e. students in class on the day of the survey with parental consent, representing an 88\% student response rate). Data were collected from October 2010 to April 2011.

\section{Procedure}

The web-based Food Behaviour Questionnaire ${ }^{(20)}$, including a $24 \mathrm{~h}$ diet recall, was used to assess nutrient intake. Participants completed the questionnaire independently in the school's computer lab over 30-40 min of class time. All surveys were completed on TuesdayFriday, to ensure weekday recalls were obtained. A trained research assistant was present to respond to questions. The $24 \mathrm{~h}$ recall collected data separately for breakfast, lunch, dinner and other times. Nutrient analysis was completed using ESHA Food Processor software and the 2007 Canadian Nutrient File (CNF) database. The CNF, as published by Health Canada, is the standard reference food composition database reporting the amount of nutrients in foods commonly consumed in Canada and is used by Statistics Canada, the Canadian Food Inspection Agency as well as many hospitals, universities and some food manufacturers. It was important to use a Canadianspecific food database, as Na levels in foods are known to differ across countries ${ }^{(21)}$. Some participants ( $n$ 44, $\sim 4 \%$ ) were excluded from further analyses because of implausible energy intake data (e.g. $\quad<837 \mathrm{~kJ} / \mathrm{d}$ $(<200 \mathrm{kcal} / \mathrm{d})$ or $>25104 \mathrm{~kJ} / \mathrm{d}(>6000 \mathrm{kcal} / \mathrm{d}))$ and/or food group intakes (e.g. determined to be false on visual inspection of any record with more than three times the upper servings recommendation $)^{(22-25)}$. Further, a measure of under-reporting was calculated using the ratio

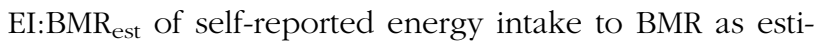
mated using the age- and sex-specific formulae outlined by the $\mathrm{WHO}^{(26)}$. Lower values of EI:BMR ${ }_{\text {est }}(v$. higher) represent more under-reporting (a reporting status cut-off of EI:BMR est $=1 \cdot 74$ has been used in previous works ${ }^{(23,27)}$ when defining as a categorical variable).

$\mathrm{Na}$ intake $(\mathrm{mg} / \mathrm{d})$ was based on the Na content of foods consumed and does not consider the potential addition of table salt. Na was used as both a continuous variable (e.g. $\mathrm{mg} / \mathrm{d}$ within food record) and a categorical variable (less than and greater than the UL of $2200 \mathrm{mg} / \mathrm{d}$ and categorized by quartiles) to denote high $\mathrm{Na}$ intakes. The classification by quartiles was done in order to better describe intakes (as most participants were already consuming levels above the UL, this does not allow for discrimination among high(er) and low(er) intakes).

All physical measures (height, weight and BP) were taken by nurses and/or nursing students (senior undergraduate or master's students). Height and weight, without shoes, were measured using a stadiometer. Measured height and weight values were used to calculate BMI using the formula BMI = weight $(\mathrm{kg}) /[\text { height }(\mathrm{m})]^{2}$, from which body weight status was classified as underweight, normal weight, overweight or obese using the newly adopted WHO guidelines ${ }^{(28)}$. BP was manually taken twice, using mercury sphygmomanometers, after participants had been sitting in a chair for at least $5 \mathrm{~min}$ and the two measures were taken at least $5 \mathrm{~min}$ apart. If the two measures differed by more than $10 \%$ a third measure was taken. The final values of systolic BP (SBP) and diastolic BP (DBP) were calculated by averaging the two closest measurements. SBP and DBP measurements were used as both a continuous variable (e.g. $\mathrm{mmHg}$ ) and a categorical variable to denote high BP (e.g. $>120 \mathrm{mmHg}$ for SBP and $>80 \mathrm{mmHg}$ for DBP).

\section{Statistical analyses}

Exploratory one-way ANOVA and $\chi^{2}$ tests were completed for the continuous and categorical descriptive data, respectively (Table 1 by gender and Table 2 by body 
weight status). Separate one-way ANOVA were used to determine the effects of $\mathrm{Na}$ intake on SBP and DBP. An ordinal regression analysis was used to determine the overall impact of SBP, DBP and daily $\mathrm{Na}$ intake (by quartiles) on body weight status, controlling for sex, ethnicity and under-reporting (i.e. adjusted model).

\section{Results}

Of the students who completed the web-based survey ( $n$ 1008), there were 522 males (52\%) and 486 females (48\%). Among them, one $(0 \cdot 1 \%)$, thirty-six (4\%), 710 (70\%), 237 (24\%) and twenty-four (2\%) reported that they were 10, 11, 12, 13 and 14 years of age, respectively. While our original aim included grade 7 students ( $n$ 897, 89\%), twenty-four grade 6 students (2\%) and eighty-seven grade 8 students (9\%) completed the study. Students represented a wide variety of ethnic backgrounds including: white (72\%), black (6\%), Arab (5\%), South Asian (3\%), Chinese (2\%) and other (12\%). The major languages spoken at home were English (88\%), French $(0 \cdot 2 \%)$, Arabic (3\%), Chinese (1\%) and other (8\%).

Table 1 describes height, weight, BMI, BMI status, SBP, prevalence of high SBP, DBP, prevalence of high DBP, ethnicity (white $v$. non-white), Na intake, prevalence of high $\mathrm{Na}$ intake, total energy intake and under-reporting status (EI:BMR ${ }_{\text {est }}$ ) by gender. Males consumed higher amounts of $\mathrm{Na}$ and more total energy than females $(P<0 \cdot 001)$, yet no differences were observed between males and females when $\mathrm{Na}$ intake was normalized over total energy intake. Among all participants, $80 \%$ and $60 \%$ had $\mathrm{Na}$ intakes above the current Adequate Intake of $1500 \mathrm{mg} / \mathrm{d}$ and UL of $2200 \mathrm{mg} / \mathrm{d}$, respectively.
Na intake, SBP and DBP are described by body weight status in Table 2 . In bivariate analyses, both SBP $(P<0 \cdot 001)$ and DBP $(P<0 \cdot 001)$ were significantly different according to body weight status, yet body weight status was not associated with $\mathrm{Na}$ intake. Furthermore, $\mathrm{Na}$ intake was not associated with either SBP or DBP. High SBP was observed in $0 \%, 3 \%, 11 \%$ and $27 \%$ and high DBP was observed in $0 \%, 1 \%, 3 \%$ and $9 \%$ of underweight, normal weight, overweight and obese participants, respectively. However, in the adjusted model (Table 3), participants were more likely to be overweight or obese if they had higher SBP (v. lower: $\mathrm{OR}=1 \cdot 06,95 \% \mathrm{CI} 1 \cdot 05,1 \cdot 08, P<0 \cdot 001$ ), higher DBP $(v$. lower: $\mathrm{OR}=1 \cdot 02,95 \%$ CI $1 \cdot 00,1 \cdot 04, P=0 \cdot 043$ ) and higher intakes of $\mathrm{Na}$ (3rd $v$. 1st quartile: $\mathrm{OR}=1 \cdot 72$, $95 \%$ CI $1 \cdot 14,2 \cdot 59, P=0 \cdot 009$; 4 th $v$. 1st quartile: $\mathrm{OR}=2 \cdot 88$, $95 \%$ CI $1 \cdot 76,4 \cdot 73, P<0 \cdot 001)$.

\section{Discussion}

Body weight status, BP (SBP and DBP) and Na intake of students in grade 7 from south-western Ontario were described through the Food Behaviour Questionnaire and physical measurements. Participants in the present study had higher rates of overweight and obesity compared with the national average ${ }^{(29)}$. Furthermore, higher SBP and DBP values were observed than what was expected, as the Canadian Health Measures Survey (CHMS) reported mean SBP and DBP of $98 \mathrm{mmHg}$ and $63 \mathrm{mmHg}$, respectively, and a rate of elevated BP of $2 \cdot 2 \%$ among $12-19$-year-olds ${ }^{(1)}$. Lastly, the current study observed higher (albeit more closely aligned than the CHMS data) SBP and DBP values than those in US children and adolescents from the National Health and Nutrition Examination Survey (NHANES III and

Table 1 Descriptor variables by gender: grade 7 students (n 1008), south-western Ontario, Canada, October 2010 to April 2011

\begin{tabular}{|c|c|c|c|c|c|c|c|}
\hline \multirow[b]{2}{*}{ Variable } & \multicolumn{2}{|c|}{ Males ( $n$ 522) } & \multicolumn{2}{|c|}{ Females ( $n$ 486) } & \multicolumn{2}{|c|}{ Total $(n$ 1008) } & \multirow[b]{2}{*}{$P^{\star}$} \\
\hline & Mean & SD & Mean & SD & Mean & SD & \\
\hline Height (m) & $1 \cdot 56$ & 0.09 & 1.56 & 0.07 & 1.56 & 0.08 & 0.687 \\
\hline Weight $(\mathrm{kg})$ & 51.59 & $2 \cdot 09$ & $51 \cdot 72$ & $12 \cdot 23$ & $51 \cdot 75$ & $13 \cdot 19$ & $0 \cdot 880$ \\
\hline Ethnicity (\% white/\% non-white) & \multicolumn{2}{|c|}{$72 / 28$} & \multicolumn{2}{|c|}{$71 / 29$} & \multicolumn{2}{|c|}{$72 / 28$} & $0 \cdot 726$ \\
\hline BMI $\left(\mathrm{kg} / \mathrm{m}^{2}\right)$ & $20 \cdot 92$ & $4 \cdot 45$ & $21 \cdot 13$ & $4 \cdot 16$ & $21 \cdot 03$ & $4 \cdot 29$ & 0.467 \\
\hline $\begin{array}{l}\text { BMI status (\% underweight } / \% \text { normal } \\
\text { weight } / \% \text { overweight } / \% \text { obese) }\end{array}$ & \multicolumn{2}{|c|}{$1 / 54 / 23 / 22$} & \multicolumn{2}{|c|}{$1 / 59 / 23 / 17$} & \multicolumn{2}{|c|}{$1 / 56 / 23 / 20$} & $0 \cdot 192$ \\
\hline $\mathrm{SBP}(\mathrm{mmHg})$ & $108 \cdot 9$ & $10 \cdot 0$ & $107 \cdot 7$ & $10 \cdot 5$ & $108 \cdot 3$ & $10 \cdot 3$ & 0.138 \\
\hline High SBP $(\%<120 \mathrm{mmHg} / \%>120 \mathrm{mmHg})$ & \multicolumn{2}{|c|}{$90 / 10$} & \multicolumn{2}{|c|}{$91 / 9$} & \multicolumn{2}{|c|}{$91 / 9$} & 0.468 \\
\hline $\mathrm{DBP}(\mathrm{mmHg})$ & $65 \cdot 9$ & $7 \cdot 7$ & $66 \cdot 1$ & $7 \cdot 3$ & $66 \cdot 0$ & $7 \cdot 5$ & 0.783 \\
\hline High DBP $(\%<80 \mathrm{mmHg} / \%>80 \mathrm{mmHg})$ & \multicolumn{2}{|c|}{$97 / 3$} & \multicolumn{2}{|c|}{$98 / 2$} & \multicolumn{2}{|c|}{$97 / 3$} & 0.444 \\
\hline $\mathrm{Na}$ intake $(\mathrm{mg} / \mathrm{d})$ & 3127 & 1696 & 2446 & 1259 & 2799 & $1538 \cdot 9$ & $<0.001$ \\
\hline Na quartile $1(\%<1679 \mathrm{mg} / \mathrm{d})$ & \multicolumn{2}{|c|}{41} & \multicolumn{2}{|c|}{59} & \multicolumn{2}{|c|}{$\mathrm{n} / \mathrm{a}$} & $<0.001$ \\
\hline Na quartile 2 (\% 679-<2540 mg/d) & \multicolumn{2}{|c|}{45} & \multicolumn{2}{|c|}{55} & \multicolumn{2}{|c|}{$\mathrm{n} / \mathrm{a}$} & \\
\hline Na quartile 3 (\% 2540-<3633 mg/d) & \multirow{2}{*}{\multicolumn{2}{|c|}{$\begin{array}{l}55 \\
67\end{array}$}} & \multicolumn{2}{|c|}{45} & \multicolumn{2}{|c|}{$\mathrm{n} / \mathrm{a}$} & \\
\hline Na quartile $4(\% \geq 3633 \mathrm{mg} / \mathrm{d})$ & & & & & & & \\
\hline High $\mathrm{Na}(\%>2200 \mathrm{mg} / \mathrm{d})$ & \multicolumn{2}{|c|}{67} & \multicolumn{2}{|c|}{52} & \multicolumn{2}{|c|}{$\begin{array}{c}\mathrm{n} / \mathrm{a} \\
60\end{array}$} & $<0.001$ \\
\hline Energy intake $(\mathrm{kJ} / \mathrm{d})$ & 8853 & 3782 & 7251 & 3230 & 8083 & 3527 & $<0.001$ \\
\hline Energy intake $(\mathrm{kcal} / \mathrm{d})$ & 2116 & 904 & 1733 & 722 & 1932 & 843 & $<0.001$ \\
\hline Under-reporting ratio (El:BMR $\left.\mathrm{Bst}_{\mathrm{est}}\right)$ & $1 \cdot 40$ & 0.60 & $1 \cdot 30$ & 0.60 & $1 \cdot 35$ & 0.60 & 0.012 \\
\hline
\end{tabular}

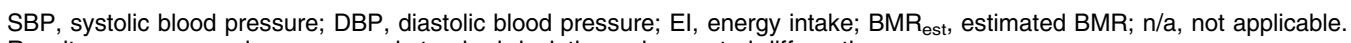

Results are expressed as mean and standard deviation unless noted differently.

*Significance of the difference between genders. 
Table 2 Descriptor variables by body weight status: grade 7 students ( $n$ 1008), south-western Ontario, Canada, October 2010 to April 2011

\begin{tabular}{|c|c|c|c|c|c|c|c|c|c|}
\hline \multirow[b]{2}{*}{ Variable } & \multicolumn{2}{|c|}{$\begin{array}{l}\text { Underweight } \\
\qquad(n 9)\end{array}$} & \multicolumn{2}{|c|}{$\begin{array}{l}\text { Normal weight } \\
\quad(n \text { 539) }\end{array}$} & \multicolumn{2}{|c|}{$\begin{array}{l}\text { Overweight } \\
\quad(n 215)\end{array}$} & \multicolumn{2}{|c|}{$\begin{array}{l}\text { Obese } \\
(n 190)\end{array}$} & \multirow[b]{2}{*}{$P^{*}$} \\
\hline & Mean & SD & Mean & SD & Mean & SD & Mean & SD & \\
\hline Gender (\% males/\% females) & \multicolumn{2}{|c|}{$67 / 33$} & \multicolumn{2}{|c|}{$50 / 50$} & \multicolumn{2}{|c|}{$52 / 48$} & \multicolumn{2}{|c|}{$58 / 42$} & $0 \cdot 192$ \\
\hline Ethnicity (\% white/\% non-white) & \multicolumn{2}{|c|}{$89 / 11$} & \multicolumn{2}{|c|}{$71 / 29$} & \multicolumn{2}{|c|}{$70 / 30$} & \multicolumn{2}{|c|}{$76 / 24$} & 0.349 \\
\hline $\mathrm{SBP}(\mathrm{mmHg})$ & $99 \cdot 1$ & $10 \cdot 6$ & $105 \cdot 4$ & $9 \cdot 3$ & $110 \cdot 0$ & $9 \cdot 1$ & $114 \cdot 4$ & $10 \cdot 8$ & $<0.001$ \\
\hline High SBP $(\%<120 \mathrm{mmHg} / \%>120 \mathrm{mmHg})$ & \multicolumn{2}{|c|}{$100 / 0$} & \multicolumn{2}{|c|}{$97 / 3$} & \multicolumn{2}{|c|}{$89 / 11$} & \multicolumn{2}{|c|}{$73 / 27$} & $<0.001 \dagger$ \\
\hline $\mathrm{DBP}(\mathrm{mmHg})$ & $62 \cdot 3$ & $4 \cdot 8$ & $64 \cdot 4$ & $7 \cdot 1$ & $67 \cdot 1$ & $7 \cdot 2$ & $69 \cdot 3$ & $7 \cdot 8$ & $<0.001$ \\
\hline High DBP $(\%<80 \mathrm{mmHg} / \%>80 \mathrm{mmHg})$ & \multicolumn{2}{|c|}{$100 / 0$} & \multicolumn{2}{|c|}{$99 / 1$} & \multicolumn{2}{|c|}{$97 / 3$} & \multicolumn{2}{|c|}{$91 / 9$} & $<0.001+$ \\
\hline $\mathrm{Na}$ intake $(\mathrm{mg} / \mathrm{d})$ & 3383 & 1331 & 2860 & 1538 & 2616 & 1572 & 2821 & 1523 & $0 \cdot 158$ \\
\hline Na quartile1 $(\%<1679 \mathrm{mg} / \mathrm{d})$ & \multicolumn{2}{|c|}{11} & \multicolumn{2}{|c|}{22} & \multicolumn{2}{|c|}{11} & \multicolumn{2}{|c|}{56} & $0 \cdot 167$ \\
\hline Na quartile $2(\% 679-<2540 \mathrm{mg} / \mathrm{d})$ & \multirow{2}{*}{\multicolumn{2}{|c|}{23}} & \multirow{2}{*}{\multicolumn{2}{|c|}{$\begin{array}{l}24 \\
28\end{array}$}} & \multirow{2}{*}{\multicolumn{2}{|c|}{$\begin{array}{l}26 \\
22\end{array}$}} & \multicolumn{2}{|c|}{27} & \\
\hline Na quartile $3(\% 2540-<3633 \mathrm{mg} / \mathrm{d})$ & & & & & & & & & \\
\hline Na quartile $4(\% \geq 3633 \mathrm{mg} / \mathrm{d})$ & \multicolumn{2}{|c|}{26} & \multicolumn{2}{|c|}{24} & \multicolumn{2}{|c|}{26} & \multicolumn{2}{|c|}{20} & \\
\hline $\mathrm{High} \mathrm{Na}(\%>2200 \mathrm{mg} / \mathrm{d})$ & \multicolumn{2}{|c|}{77} & \multicolumn{2}{|c|}{61} & & & & & 0.257 \\
\hline Energy intake $(\mathrm{kJ} / \mathrm{d})$ & 10305 & 2364 & 8439 & 3594 & 7673 & 3628 & 7456 & 3138 & $<0.001$ \\
\hline Energy intake $(\mathrm{kcal} / \mathrm{d})$ & 2463 & 565 & 2017 & 859 & 1834 & 867 & 1782 & 750 & $<0.001$ \\
\hline Under-reporting ratio (El:BMR $\left.\mathrm{Bst}_{\text {est }}\right)$ & $2 \cdot 04$ & 0.50 & 1.49 & 0.60 & $1 \cdot 24$ & 0.60 & $1 \cdot 05$ & $0 \cdot 40$ & $<0.001$ \\
\hline
\end{tabular}

SBP, systolic blood pressure; DBP, diastolic blood pressure; El, energy intake; BMR ${ }_{\text {est }}$, estimated BMR.

Results are expressed as mean and standard deviation unless noted differently.

* Significance of the difference among weight status groups.

tAnalysis was completed without the underweight participants due to small sample size.

Table 3 Associations among body weight status categories and systolic and diastolic blood pressure, sodium intake quartiles and descriptor variables: grade 7 students (n 1008), south-western Ontario, Canada, October 2010 to April 2011

\begin{tabular}{lccc}
\hline Variable & OR & $95 \% \mathrm{Cl}$ & $P^{\star}$ \\
\hline $\begin{array}{l}\text { Sex } \\
\quad \text { Male v. female }\end{array}$ & 0.82 & $0.63,1.08$ & 0.153 \\
$\begin{array}{l}\text { Ethnicity } \\
\quad \text { White } v \text {. non-white }\end{array}$ & 1.05 & $0.78,1.41$ & 0.760 \\
$\begin{array}{l}\text { Under-reporting ratio } \\
\quad \text { El:BMR }\end{array}$ & 0.21 & $0.15,0.30$ & $<0.001$ \\
$\begin{array}{l}\text { SBP } \\
\text { mmHg }\end{array}$ & 1.06 & $1.05,1.08$ & $<0.001$ \\
$\begin{array}{l}\text { DBP } \\
\quad \text { mmHg }\end{array}$ & 1.02 & $1.00,1.04$ & 0.043 \\
$\begin{array}{l}\text { Na quartile 1 } \\
\quad<1679 \text { mg/d }\end{array}$ & 1.00 & Ref. & - \\
$\begin{array}{l}\text { Na quartile 2 } \\
\quad 1697-<2540 \mathrm{mg} / \mathrm{d}\end{array}$ & 1.26 & $0.86,1.83$ & 0.238 \\
$\begin{array}{l}\text { Na quartile 3 } \\
\quad 2540-<3633 \mathrm{mg} / \mathrm{d}\end{array}$ & 1.72 & $1.14,2.59$ & 0.009 \\
$\begin{array}{l}\text { Na quartile 4 } \\
\quad \geq 3633 \mathrm{mg} / \mathrm{d}\end{array}$ & 2.88 & $1.76,4.73$ & $<0.001$ \\
\hline
\end{tabular}

SBP, systolic blood pressure; DBP, diastolic blood pressure; El, energy intake; $\mathrm{BMR}_{\mathrm{est}}$, estimated BMR; Ref., referent category.

*Significance of the variable on body weight status category adjusted for all other variables in the model.

NHANES IV), which reported $107 \cdot 0 / 57 \cdot 8 \mathrm{mmHg}$ (males) and $103 \cdot 1 / 58 \cdot 0 \mathrm{mmHg}$ (females) ${ }^{(30)}$. Differences in the manner of measuring BP (e.g. a quiet room in the absence of staff as per the CHMS $v$. in a school setting) may have contributed to the differences in $\mathrm{BP}$ observations between studies.

Similar to others ${ }^{(6,30-33)}$, the current study observed higher BP measures among overweight/obese individuals. Excess weight is believed to influence BP through increased sympathetic nervous system activation ${ }^{(1)}$. While the strength of evidence is fairly strong for the association between $\mathrm{BP}$ and body weight status ${ }^{(34)}$, Chiolero et al. $^{(35)}$ argue that the increase in BP measures has not paralleled the increase in body weight status over time. Further, other factors besides body weight status may influence BP such as low birth weight ${ }^{(36)}$, which was not studied in the current project. Regardless, among the overweight and obese participants, 36\% had at least one high measure of SBP or DBP and $7 \%$ had both high SBP and high DBP, which may further exacerbate the cardiovascular health risks.

Interestingly, Na intake was not associated with BMI or BP in the bivariate analyses; however, it became positively associated in the adjusted model. The mechanistic influence of $\mathrm{Na}$ intake on BP is not fully understood, yet seems to be related to the inability of the kidneys to excrete large amounts of salt ${ }^{(37)}$, thus increasing overall blood volume. Significant ${ }^{(38,39)}$ and insignificant ${ }^{(40)}$ associations between $\mathrm{Na}$ intake and $\mathrm{BP}$ have been observed in the past, yet the inconsistencies are largely attributed to different methodologies. Further, several studies show mixed results for different age groups $^{(41,42)}$ or between genders ${ }^{(43)}$. The results of the current study are based on a single $24 \mathrm{~h}$ diet recall and do not represent usual or long-term $\mathrm{Na}$ intake. Although high $\mathrm{Na}$ intakes are often reported among children/adolescents, high intra-individual daily variability could exist, thus displaying no relationships. Furthermore, there are inherent limitations in any nutrition survey. Self-reported survey data have the potential for recall error, inaccurate estimation of portion sizes, systematic bias in dietary reporting and providing socially desirable answers. The Food Behaviour Questionnaire was designed to minimize these limitations, and we have tried to account for some of the under-reporting in the analyses. Finally, it 
is recognized that the current findings are limited to the amounts of $\mathrm{Na}$ as designated by the CNF.

According to He and MacGregor ${ }^{(44)}, 24 \mathrm{~h}$ urine collections are the most accurate method of assessing dietary salt intake. Studies using this methodology have also produced significant ${ }^{(45-47)}$ and insignificant ${ }^{(48,49)}$ associations between $\mathrm{Na}$ intake and BP. For example, among older children, Cooper et al. ${ }^{(45)}$ reported a significant linear relationship between urinary Na and SBP in seventy-three 11-14-year-olds, even after controlling for confounding variables such as height, weight, pulse, age, sex and race. Due to the nature of the current study (and many other population/epidemiological studies), urinary $\mathrm{Na}$ measurements are not possible in the field, which may limit findings in large-scale studies.

There is a dearth of studies investigating the relationships among body weight status, BP and $\mathrm{Na}$ intake in children/ adolescents, making it difficult to compare the results of the current study. Among longitudinal/intervention trials, Khang and Lynch ${ }^{(50)}$ could not attribute the decreases in BP to nutritional intake (e.g. $\mathrm{Na}, \mathrm{K}$, total energy, protein and fat intake) even though they observed a reduction ( 8-10 mmHg for SBP) over the past 10 years among Korean children and adolescents. A recent meta-analysis reported that a reduction of salt intake by $42 \%(3 \mathrm{~g} / \mathrm{d})$ causes a fall in SBP of $1.2 \mathrm{mmHg}^{(44)}$; however, body weight status was not accounted for, thus limiting the findings to the current study. Interestingly, Rocchini et al. ${ }^{(51)}$ reported lower mean arterial BP among obese boys (but not among normal weight boys) in a low-Na intervention. Several review papers ${ }^{(52-54)}$ convey that reducing salt intake from the diet will lower BP, regardless of gender, age or ethnicity. The $\mathrm{Na}$ intake in the present study was high (e.g. $60 \%$ of males and $41 \%$ of females were above the UL) without the addition of any table salt, suggesting that early education and/or intervention is necessary. Nutrition behaviours learned during childhood and adolescence are known to track into adulthood ${ }^{(55-57)}$, thereby emphasizing the importance of learning healthy eating habits early on in life.

\section{Conclusion}

High intakes of Na, coupled with high SBP and DBP, were associated with overweight and obesity status among the grade 7 sample from south-western Ontario, Canada. Health promotion strategies aimed at overweight and obese children should include BP screening and education, with a key focus on balancing physical activity with healthy nutritional daily practices.

\section{Acknowledgements}

Sources of funding: This research was supported by Southwestern Ontario in Motion, the Department of Kinesiology and the Faculty of Nursing at the University of Windsor. Conflicts of interest: The authors declare no conflicts of interest. Authors' contributions: All authors contributed to the design, data collection and approved the manuscript.

\section{References}

1. Paradis G, Tremblay MS, Janssen I et al. (2010) Blood pressure in Canadian children and adolescents. Health Rep 21, 15-22.

2. Maximova K, O'Loughlin J, Paradis G et al. (2010) Changes in anthropometric characteristics and blood pressure during adolescence. Epidemiology 21, 324-331.

3. McCrindle BW, Manlhiot C, Millar K et al. (2010) Population trends toward increasing cardiovascular risk factors in Canadian adolescents. J Pediatr 157, 837-843.

4. Paradis G, Lambert M, O'Loughlin J et al. (2004) Blood pressure and adiposity in children and adolescents. Circulation 110, 1832-1838.

5. Salvadori M, Sontrop JM, Garg AX et al. (2008) Elevated blood pressure in relation to overweight and obesity among children in a rural Canadian community. Pediatrics 122, e821-e827.

6. Gopinath B, Baur LA, Garnett S et al. (2011) Body mass index and waist circumference are associated with blood pressure in preschool-aged children. Ann Epidemiol 21, 351-357.

7. Chen X \& Wang Y (2008) Tracking of blood pressure from childhood to adulthood: a systematic review and metaregression analysis. Circulation 117, 3171-3180.

8. Cruickshank JK, Mzayek F, Liu L et al. (2005) Origins of the 'black/white' difference in blood pressure: roles of birth weight, postnatal growth, early blood pressure, and adolescent body size: the Bogalusa Heart Study. Circulation 111, 1932-1937.

9. Lauer FM, Burns TL, Clarke WR et al. (1991) Childhood predictors of future blood pressure. Hypertension 18, 174-181.

10. Burke V, Beilin LJ, Dunbar D et al. (2004) Associations between blood pressure and overweight defined by new standards for body mass index in childhood. Prev Med $\mathbf{3 8}$, 558-564.

11. Juonala M, Magnussen CG, Berenson GS et al. (2011) Childhood adiposity, adult adiposity, and cardiovascular risk factors. $N$ Engl J Med 365, 1876-1885.

12. Lauer RM, Mahoney LT \& Clarke WR (1986) Tracking of blood pressure during childhood: the Muscatine Study. Clin Exp Hypertens $A$ 8, 515-537.

13. Ekelund U, Luan J, Sherar LB et al; International Children's Accelerometry Database (ICAD) Collaborators (2012) Moderate to vigorous physical activity and sedentary time and cardiometabolic risk factors in children and adolescents. JAMA 307, 704-712.

14. Holman RM, Carson V \& Janssen I (2011) Does the fractionalization of daily physical activity (sporadic vs. bouts) impact cardiometabolic risk factors in children and youth? PLoS One 6, e25733.

15. Sugiyama T, Xie D, Graham-Maar RC et al. (2007) Dietary and lifestyle factors associated with blood pressure among US adolescents. J Adolesc Health 40, 166-172.

16. Stabelini Neto A, Sasaki JE, Mascarenhas LP et al. (2011) Physical activity, cardiorespiratory fitness, and metabolic syndrome in adolescents: a cross-sectional study. BMC Public Health 11, 674.

17. Garriguet D (2007) Sodium consumption at all ages. Health Rep 18, 47-52.

18. Tanase CM, Koski KG, Laffey PJ et al. (2011) Canadians continue to consume too much sodium and not enough potassium. Can J Public Health 102, 164-168. 
19. Veugelers PJ, Fitzgerald AL \& Johnston E (2005) Dietary intake and risk factors for poor diet quality among children in Nova Scotia. Can J Public Health 96, 212-216.

20. Hanning RM, Royall D, Toews JE et al. (2009) Web-based Food Behaviour Questionnaire: validation with grades six to eight students. Can J Diet Pract Res 70, 172-178.

21. Dunford E, Webster J, Woodward M et al. (2012) The variability of reported salt levels in fast foods across six countries: opportunities for salt reduction. CMAJ 184, 1023-1028.

22. Hanning RM, Woodruff SJ, Lambraki I et al. (2007) Nutrient intakes and food consumption patterns among Ontario students in grades six, seven, and eight. Can J Public Health 98, 12-16.

23. Vance VA, Woodruff SJ, McCargar LJ et al. (2009) Self-reported dietary energy intake of normal weight, overweight, and obese adolescents. Public Health Nutr 12, 222-227.

24. Woodruff SJ, Hanning RM, Lambraki I et al. (2008) Healthy Eating Index-C is compromised among adolescents with body weight concerns, weight loss dieting, and meal skipping. Body Image 5, 404-408.

25. Woodruff SJ, Hanning RM, McGoldrick K et al. (2010) Healthy Eating Index-C is positively associated with family dinner frequency among students in grades 6-8 from Southern Ontario, Canada. Eur J Clin Nutr 64, 454-460.

26. World Health Organization (1985) Energy and Protein Requirements. Report of a Joint FAO/WHO/UNU Expert Consultation. WHO Technical Report Series no. 724. Geneva: WHO.

27. Black AE (2000) Critical evaluation of energy intake using the Goldberg cut-off for energy intake:basal metabolic rate. A practical guide to its calculation, use and limitations. Int J Obes Relat Metab Disord 24, 1119-1130.

28. de Onis M, Onyango AW, Borghi E et al. (2007) Development of a WHO growth reference for school-aged children and adolescents. Bull World Health Organ 85 , 660-667.

29. Shields M \& Tremblay MS (2010) Canadian childhood obesity estimates based on WHO, IOTF and CDC cut-points. Int $J$ Pediatr Obes 5, 265-273.

30. Going SB, Lohman TG, Cussler EC et al. (2011) Percent body fat and chronic disease risk factors in US children and youth. Am J Prev Med 41, 4 Suppl. 2, S77-S86.

31. Delmis J (2010) Effect of diet and salt intake on the development of hypertension in children and adolescents. Acta Med Croatica 64, 111-114.

32. Kollias A, Skliros E, Stergiou GS et al. (2011) Obesity and associated cardiovascular risk factors among schoolchildren in Greece: a cross-sectional study and review of the literature. J Pediatr Endocrinol Metab 24, 929-938.

33. Moore WE, Eichner JE, Cohn EM et al. (2009) Blood pressure screening of school children in a multiracial school district: the Healthy Kids Project. Am J Hypertens 22, 351-356.

34. Couch SC \& Daniels SR (2005) Diet and blood pressure in children. Curr Opin Pediatr 17, 642-647.

35. Chiolero A, Bovet P, Paradis G et al. (2007) Has blood pressure increased in children in response to the obesity epidemic? Pediatrics 119, 544-553.

36. Lurbe E, Carvajal E, Torro I et al. (2009) Influence of concurrent obesity and low birth weight on blood pressure phenotype in youth. Hypertension 53, 912-917.
37. Meneton P, Jeunemaitre X, de Wardener HE et al. (2005) Links between dietary salt intake, renal salt handling, blood pressure, and cardiovascular diseases. Physiol Rev 85, 679-715

38. Gillman MW, Oliveria SA, Moore LL et al. (1992) Inverse association of dietary calcium with systolic blood pressure in young children. JAMA 267, 2340-2343.

39. Jenner DA, English DR, Vandongen $\mathrm{R}$ et al. (1988) Diet and blood pressure in 9-year-old Australian children. Am J Clin Nutr 47, 1052-1059.

40. Simons JA, Obarzanek E, Daniels SRA et al. (1994) Dietary cation intake and blood pressure in black girls and white girls. Am J Epidemiol 139, 130-140.

41. He FJ, Marrero NM \& Macgregor GA (2008) Salt and blood pressure in children and adolescents. J Hum Hypertens 22, 4-11.

42. Persson LA (1984) Dietary habits and health risks in Swedish children. Hum Nutr Clin Nutr 38C, 287-297.

43. Tucker DT, Smothers M, Lewis C et al. (1989) Effects of decreased dietary salt intake on blood pressure in preschool children. J Natl Med Assoc 81, 299-302.

44. He FJ \& MacGregor GA (2006) Importance of salt in determining blood pressure in children: meta-analysis of controlled trials. Hypertension 48, 861-869.

45. Cooper R, Soltero I, Liu K et al. (1980) The association between urinary sodium excretion and blood pressure in children. Circulation 62, 97-104.

46. Faust HS (1982) Effects of drinking water and total sodium intake on blood pressure. Am J Clin Nutr 35, $1459-1467$.

47. Watson RL, Langford HG, Abernethy J et al. (1980) Urinary electrolytes, body weight, and blood pressure: pooled cross-sectional results among four groups of adolescent females. Hypertension 2, 193-198.

48. Armstrong BK, Margetts BM, McCall MG et al. (1982) Water sodium and blood pressure in rural school children. Arch Environ Health 37, 236-245.

49. Ellison RC, Sosenko JM, Harper GP et al. (1980) Obesity, sodium intake, and blood pressure in adolescents. Hypertension 2, 178-182.

50. Khang YH \& Lynch JW (2011) Exploring determinants of secular decreases in childhood blood pressure and hypertension. Circulation 124, 397-405.

51. Rocchini AP, Key J, Bondie D et al. (1989) The effect of weight loss on the sensitivity of blood pressure to sodium in obese adolescents. $N$ Engl J Med 321, 580-585.

52. Cappuccio FP, Capewell S, Lincoln P et al. (2011) Policy options to reduce population salt intake. BMJ 343, d4995.

53. Mitsnefes MM (2006) Hypertension in children and adolescents. Pediatr Clin North Am 53, 493-512, viii.

54. Feber J \& Ahmed M (2010) Hypertension in children: new trends and challenges. Clin Sci (Lond) 119, 151-161.

55. Larson NI, Neumark-Sztainer D, Hannan PJ et al. (2007) Family meals during adolescence are associated with higher diet quality and healthful meal patterns during young adulthood. J Am Diet Assoc 107, 1502-1510.

56. Nicklas T \& Johnson R (2004) Position of the American Dietetic Association: dietary guidance for healthy children ages 2 to 11 years. J Am Diet Assoc 104, 660-677.

57. Story M, Neumark-Sztainer D \& French S (2002) Individual and environmental influences on adolescent eating behaviors. J Am Diet Assoc 102, 3 Suppl., S40-S51. 